\title{
Something is lost and something is gained: loss and replacement of species and functional groups in ant communities at fragmented forests
}

\author{
Ezequiel González $(\mathbb{D} \cdot$ Liliana Buffa $\cdot$ María Teresa Defagó • Silvia Itatí Molina • \\ Adriana Salvo $\mathbb{D} \cdot$ Graciela Valladares
}

Received: 30 July 2018/Accepted: 3 October 2018/Published online: 9 October 2018

(C) Springer Nature B.V. 2018

\begin{abstract}
Context Small fragments of natural habitats with an increased proportion of edges are common landscape traits following agricultural expansion. Consequences of habitat fragmentation are widely documented. However, functional and mechanistic approaches are still needed in order to understand these changes.

Objectives We studied habitat loss and edge effects on ant communities, addressing changes in species and functional group diversity, and the relative importance of $\beta$-diversity components.
\end{abstract}

Electronic supplementary material The online version of this article (https://doi.org/10.1007/s10980-018-0724-y) contains supplementary material, which is available to authorized users.

E. González ( $₫)$

Faculty of Environmental Sciences, Czech University of Life Sciences Prague, Kamýcká 129,

Prague, Suchdol 165 00, Czech Republic

e-mail: ezenofx@gmail.com

E. González · M. T. Defagó · A. Salvo · G. Valladares Centro de Investigaciones Entomológicas de Córdoba, Instituto Multidisciplinario de Biología Vegetal, Universidad Nacional de Córdoba, CONICET, FCEFyN, Av. Velez Sarsfield 1611, 5000 Córdoba, Argentina

L. Buffa · M. T. Defagó · S. I. Molina · A. Salvo Cátedra de Entomología, Universidad Nacional de Córdoba, FCEFyN, Av. Velez Sarsfield 299,

5000 Córdoba, Argentina
Methods In an endangered Neotropical forest, we sampled ants in edge and interior habitats using pitfall traps, during three summers (28 sites). We calculated taxonomic, phylogenetic and functional diversity and partitioned taxonomic and functional $\beta$-diversity into replacement and loss/gain components.

Results We found more species and functional groups at edge than interior habitats, and four species were edge indicators. Habitat loss negatively affected total abundance and that of particular functional groups (fungus-growers and cryptic species) but had a positive effect on taxonomic, phylogenetic and functional diversity as well as abundance of opportunists and predators. Species and functional group replacement drove $\beta$-diversity, being linked to habitat loss. However, interactions between habitat loss and edges explained the loss/gain of taxonomic and functional composition.

Conclusions Fragmentation led to enriched ant communities at edges, possibly resulting from a higher influx of matrix species as edges become pervasive. This highlights the need to assess the spillover between habitats to understand its influence. Moreover, species replacement and the decrease of functional groups due to habitat loss could have an impact on ecosystem processes in which ants play an important role. 
Keywords Ants - $\beta$-diversity components - Chaco Serrano $\cdot$ Edge effects $\cdot$ Functional groups $\cdot$ Habitat loss

\section{Introduction}

Agricultural expansion and intensification have driven natural habitat loss all over the world (Tilman et al. 2001), dramatically threatening terrestrial biodiversity in the process, as simplified landscapes and remaining small patches of natural habitats are usually linked to impoverished species richness (Pimm and Raven 2000; Fahrig 2003). In addition, edge habitats have become dominant landscape components as a consequence of habitat fragmentation, i.e. the breaking apart of a habitat in smaller fragments (Fahrig 2003), as exemplified by $70 \%$ of forests being currently within one kilometer from an edge (Haddad et al. 2015). Edges frequently support higher biodiversity than adjacent habitats (Wirth et al. 2008), with species from both adjacent habitats as well as edge specialists (Duelli and Obrist 2003). Furthermore, edges facilitate an intense exchange of organisms from one habitat to another (Rand et al. 2006; González et al. 2016), which may affect ecosystem processes (Blitzer et al. 2012).

Ants (Insecta: Formicidae) are one of the most familiar and relevant biological groups in terrestrial ecosystems, due to their high abundance, the variety of habitats they colonize (Hölldobler and Wilson 1990) and the diverse ecosystem processes in which they participate (Folgarait 1998). Species in this family play an important role as providers of ecosystem services such as seed dispersal, biological control of pests and engineering of soil habitats, which are prone to be affected by habitat disturbance (Philpott et al. 2010). Negative effects of habitat loss on ant abundance and/or richness have been reported (Majer et al. 1997; Dunn 2004; Perfecto et al. 2007), although inconsistent responses have been noticed (Philpott et al. 2010). On the other hand, ant communities at edges are generally associated with higher species richness (Dejean and Gibernau 2000; Vasconcelos et al. 2001; Barrera et al. 2015) and different species composition (Suarez et al. 1998; Carvalho and Vasconcelos 1999; Vasconcelos et al. 2001; Debuse et al.
2007; Barrera et al. 2015) in comparison with communities at interior habitats.

Changes in community composition are usually evaluated using beta diversity indices, which measure the similarity or dissimilarity between sites or habitats. This beta diversity can be divided into components that are in turn linked to the mechanisms underlying community differences, by indicating either replacement of species between sites or species loss (Gaston and Blackburn 2000). The response of beta diversity components to environmental factors (Soininen et al. 2018) has been recently explored for ant communities (Bishop et al. 2015; Schmidt et al. 2017). However, to our knowledge, no study has yet simultaneously evaluated the influence of habitat loss and edge effects on taxonomic and functional diversity of ant communities, while incorporating beta diversity components in order to disentangle such effects.

In Argentina, natural habitats have suffered remarkably high deforestation rates in the last decades (Grau et al. 2008), and the Chaco Serrano forests in Córdoba province are one clear example: more than $94 \%$ of its original cover has been lost due to agricultural expansion (Zak et al. 2004, 2008). In this context, negative effects of habitat loss were detected for insect communities in the forest (Cagnolo et al. 2009; González et al. 2015a, 2017b) and the crop matrix (González et al. 2015b, 2017a). However, most groups showed a positive edge effect, which was also related to large numbers of insects moving between forest and adjacent crops (González et al. 2016). In this region, higher species richness and nest abundance of leafcutter ants were observed at forest edges, with fewer nests in smaller forest fragments, whereas species composition reflected both area and edge effects (Barrera et al. 2015). However, we still know little about the responses of most ant species.

Here, we analyze habitat loss and edge effects on ground-dwelling ant communities in fragmented Chaco Serrano forests from Central Argentina. We ask: (1) does ant diversity or abundance in the fragmented forest show changes linked to habitat loss or edge effects? (2) Given the wide variety of ecological roles played by ants, are there differential responses among functional groups? (3) Does taxonomic or functional composition of ant communities reflect habitat loss or edge effects and if so, which mechanism is more important: species replacement or species loss/gain? 
Considering the frequent negative effects of habitat loss on biodiversity, we expected ant communities to be more diverse and abundant in forest-dominated sites and larger forest fragments. Moreover, since particular resources could be lost as forest area decreases, we expected relatively specialized functional groups such as predator or fungus-growing ants to be more affected by habitat loss than generalized, omnivorous species. With regard to edge effects, the generalist habits of many ant species and the preference for edge habitats found in other studies led us to expect higher richness and abundance at the edge than at the forest interior. We also expected differences in community composition between forest edge and interior, resulting from species or functional groups replacement (involving habitat specialists) and species gain at the edges (due to the addition of matrix species). On the other hand, habitat loss effects on community composition might be driven mainly by the loss of particular species or functional groups as forest amount decreases.

\section{Materials and methods}

\section{Study area and ant sampling}

The study was conducted at Córdoba province, in central Argentina $\left(-31.10^{\circ}\right.$ to $31.30^{\circ} \mathrm{S}$ and $-64^{\circ}$ to $64.30^{\circ} \mathrm{W}$ ). The region belongs to the Chaco Serrano phytogeographical district, with average monthly temperatures between $26^{\circ} \mathrm{C}$ (maximum) and $10{ }^{\circ} \mathrm{C}$ (minimum), and $750 \mathrm{~mm}$ annual rainfall (Cabido et al. 1991). Ant sampling was performed in three summer seasons (December-March 2004, 2009, 2010). A total of 28 sites $(2004 \mathrm{n}=7 ; 2009 \mathrm{n}=12 ; 2010 \mathrm{n}=9)$, each consisting of a forest fragment, isolated for at least 40 years and surrounded by annual crops (maize or soybean), were selected using Landsat Thematic Mapper images and field corroboration. At each site, two positions were sampled: edge (first five meters of the forest fragment) and interior ( $25 \mathrm{~m}$ from the edge). Two measures of habitat loss were calculated: (i) the area of the forest fragment and (ii) the proportion of forest in a landscape circle (500 m diameter) around the edge sampling point of each fragment. Fragment area is a patch-scale measure of habitat amount, whereas forest cover is a landscape-scale measurement that considers the relative amount of forest (including other fragments) and non-forest habitat (McGarigal and Cushman 2002; Fahrig 2003). The $500 \mathrm{~m}$ scale was selected based on previous studies on insect response to fragmentation in the same region (González et al. 2015b, 2016, 2017b) and in order to avoid overlapping among sites. Sites were separated on average by $2.47 \mathrm{~km}( \pm 0.5)$.

Ant communities were sampled using pitfall traps (Southwood and Henderson 2000) consisting of $350 \mathrm{ml}(8.5 \mathrm{~cm}$ diameter, $10 \mathrm{~cm}$ depth) plastic cups, filled with $20 \%$ ethylene glycol. At each site, three traps were placed at the edge and three at the interior, except for one site in 2004 that had six traps at each position (174 in total, of which 19 were lost, thus 155 traps were analyzed). The higher number of traps in the latter site was intended to compensate for potential trap damage caused by small mammals, as previously observed at this site. Traps were placed at least 10 meters from each other and left exposed for 7 days. The sampling period was similar among the 3 years (between December 15th and January 15th) in order to avoid intra-season temporal differences.

After exposure, traps were taken to the laboratory, where the contents were filtered and cleaned, and ants were separated and preserved in tubes with $70 \%$ ethanol. Ant specimens were identified to species level when possible using keys (Fernández 2003) and collections from the Entomology Department of Universidad Nacional de Córdoba (Entocor), where reference material from this study has also been deposited. When species-level identification was not possible, genus and morphospecies, based on physical characteristics of each specimen, were used (see Table A1). Specimens were further assigned to functional groups based on literature and information from local species (Table A2). By considering the classification of functional groups proposed by Andersen (1995) adjusted to Neotropical species (Brandão et al. 2012; Claver et al. 2014), we determined eight functional groups: granivores, fungus-growers (including leaf-cutters), predators, generalized Myrmicinae, subordinate Camponotini, dominant Dolichoderinae, cryptic and opportunist species (Table A2). This classification considers both ecological behavior and diet of the species and it is also related to responses to disturbance. For more details of the characteristics of each group, see Andersen (1995) and Brandão et al. (2012). 
Statistical analyses

To analyze the effects of habitat loss and edges, we used the abundance and species richness per trap (total and for each functional group) as response variables in Generalized Linear Mixed Models (GLMMs), with Poisson error distribution and log link function, or a negative binomial error distribution when overdispersion was detected. For functional groups with small abundances, in order to avoid zero inflation, we used mean abundance and richness per site and position, and a Gaussian error distribution. Since forest cover proportion and fragment area (log-transformed) were correlated $(\mathrm{r}=0.81 ; \mathrm{p}<0.001)$, we ran independent models with one of these variables and edge/interior position (hereafter, position) and compared them in order to select the one with highest support. We included year, site and position as nested random factors (to account for the nested design and data dependence), and the interaction between position and landscape variables (to test for differences in slopes between edge and interior). In order to search for effects on community structure beyond species number, we performed similar models using other indicators of diversity: Simpson's diversity and Pielou's evenness indices (Magurran 2004). Since some traps collected zero ants and this affected diversity calculations, we used mean abundance of each species per site and position to calculate these indices, which were then used as response variables in GLMMs as described above, but using a Gaussian error distribution instead.

In addition to the metrics mentioned above, we calculated measures of taxonomic distinctness, which evaluate the abundance and identity of the species and their phylogenetic relationships based on taxonomic distances (Warwick and Clarke 1995). We considered subfamily, tribe, genus and species as taxonomic levels and used abundance data to calculate three indices: (i) phylogenetic diversity $(\Delta)$, which measures the diversity of ant assemblages considering both abundance and phylogenetic distance between species; (ii) phylogenetic richness ( $\Delta++$ ), comparable to species richness but incorporating the phylogenetic relationships between species; and (iii) phylogenetic evenness $(\Lambda)$, which measures the degree to which species are evenly distributed among the higher categories. Warwick and Clarke (1995) originally called these indices taxonomic diversity, total taxonomic diversity and variation of the taxonomic diversity, respectively. However, here we renamed them for clarity, highlighting the phylogenetic approach.

In order to analyze changes in ant community composition through beta diversity, we calculated the dissimilarity between sites and locations using the Bray-Curtis index and then performed an abundancebased partition of this dissimilarity to assess differences due to balanced variation in species abundance ( $\beta_{\text {bal }}$ indicative of turnover or species replacement for incidence-based patterns) and abundance gradient ( $\beta_{\text {gra }}$ indicative of species loss or nestedness; Baselga 2010, 2013, 2017), which in turn allows calculating the relative contribution of these beta components. Partitioning was performed with species-sites and functional groups-sites matrices. We then performed a partial distance-based redundancy analysis (db-RDA; Legendre and Anderson 1999) with the three dissimilarity matrices, using position (edge/interior), area or forest proportion and paired interactions as independent variables. Since we were not interested in temporal changes between sampling years, year was included as a conditional factor to exclude its influence on community composition. The measures of beta diversity were calculated using the betapart package (Baselga and Orme 2012), while the db-RDA was performed with the vegan package (Oksanen et al. 2013). Finally, in order to determine if any particular species were linked to forest edges or interiors, we performed an Indicator Species Analysis with the indicspecies package (De Cáceres et al. 2016).

Generalized linear mixed models were performed with the packages lme 4 and nlme (Bates and Sarkar 2007; Pinheiro et al. 2013). For model comparisons, AICc values (Akaike information criterion with correction for finite sample size; Hurvich and Tsai 1989) were considered, using the package MuMIn (Barton 2009), and autocorrelation was checked using variograms of the residuals (Zuur et al. 2009). In each case, the model with the lowest value of AICc was selected. As some of the best models included variables that were not significant $(0.05<\mathrm{p}<0.1)$, we refer to this cases as tendencies or marginal relationships. Figures of predicted effects were drawn using the packages effects (Fox 2003) and visreg (Breheny and Burchett 2016). All analyses were performed using the software $\mathrm{R}$ (version 3.1.1; $\mathrm{R}$ Development Core Team 2008). 


\section{Results}

Taxonomic diversity

We collected a total of 4247 ants belonging to 58 species (Table A1). Acromyrmex lundii (Mirmicinae; Attini) was the most abundant species (47.4\% of total abundance), followed by Pheidole cordiceps (7.8\%) and Pheidole sp.7 (5.4\%). The forest edge presented more species and individuals than the interior (Fig. 1a, b; Table 1), while forest cover was also included in the best model for abundance, although it was only a marginal relationship (Fig. 1c; Table 1). Taxonomic diversity, measured with the Simpson index, showed a non-signficant tendency to higher values at the edges (Fig. 1d; Table 1), whereas both diversity and evenness were negatively related to forest cover (Fig. 1e, f; Table 1). Indicator species analysis showed no species strongly associated with forest interior, whereas four indicator species were assigned to edge habitats: Pheidole rosae, Dorymyrmex sp.1, Brachymyrmex sp. 1 and Apterostigma sp. 1 (Table A3).

Phylogenetic diversity

Phylogenetic richness was higher at the edge (Fig. 2a; Table 1), whereas phylogenetic diversity decreased as forest cover increased only in the forest interior (significant position $\mathrm{x}$ forest cover interaction) (Fig. 2b; Table 1). Phylogenetic evenness was not related to any of the explanatory variables (Table 1).

Functional diversity

Within functional groups, generalized Myrmicinae was the most diverse, with 22 species. The remaining groups contained three to seven species (Table A1). Fungus-growing ants were the most abundant group a Total richness

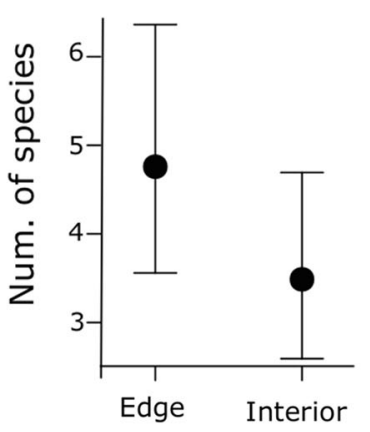

d Simpson Diversity

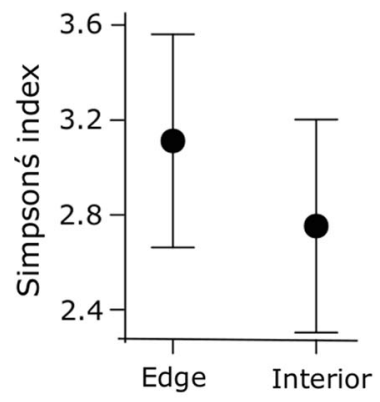

b Total abundance
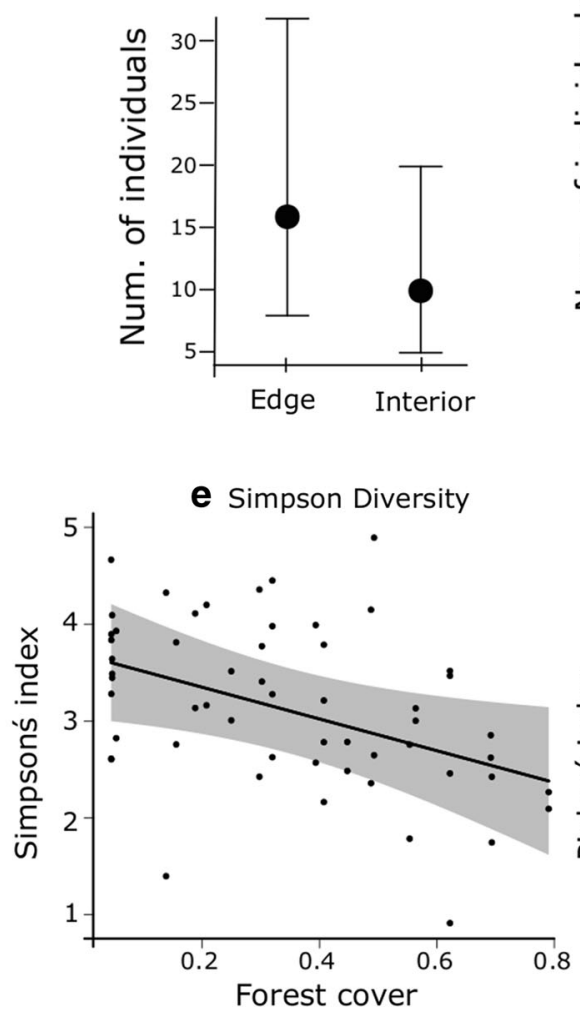

C Total abundance
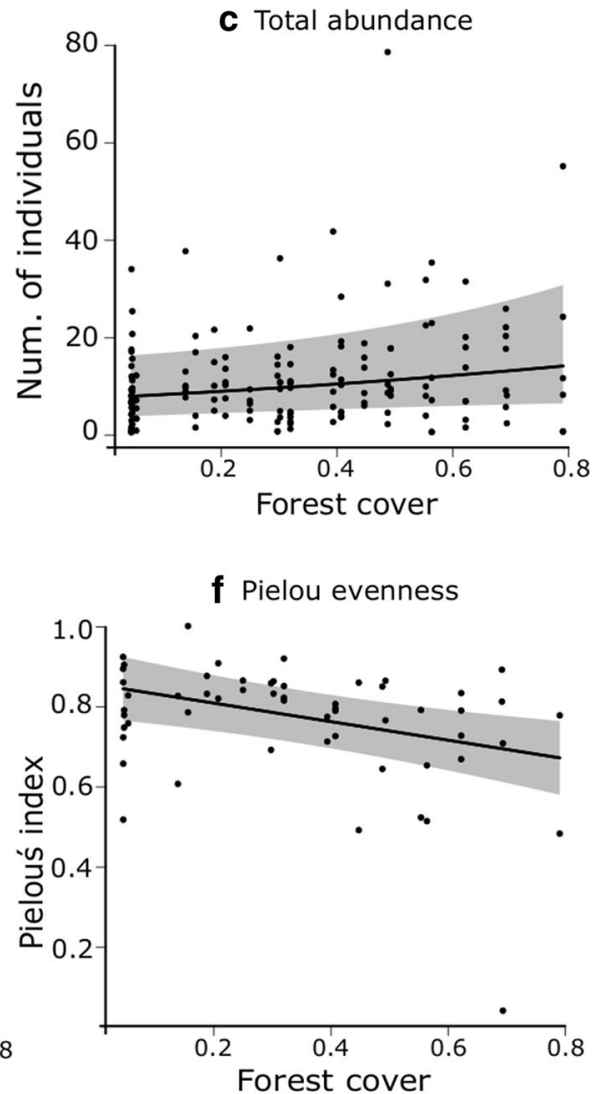

Fig. 1 Total richness (a), abundance (b, c), Simpson's diversity index (d, e), and Pielou's evenness index (f) of ant communities in fragmented Chaco Serrano forest (mean per trap $\pm 95 \% \mathrm{CI}$ ).
Habitat loss (slopes $\pm 95 \% \mathrm{CI}$ and partial residuals) and edge effects (mean $\pm 95 \% \mathrm{CI}$ ) are shown 
Table 1 Effects of habitat loss and edge/interior position on ant communities in fragmented Chaco Serrano forest

\begin{tabular}{|c|c|c|c|}
\hline Response variable $^{\mathrm{a}}$ & Independent variables ${ }^{\mathrm{b}}$ & $P$ value & Estimates $( \pm \mathrm{SE})$ \\
\hline Total richness $(\mathrm{p})$ & Position & $<0.001$ & $\begin{array}{l}1.55 \pm 0.15 \text { (edge) } \\
1.24 \pm 0.09 \text { (interior) }\end{array}$ \\
\hline Total abundance (nb) & $\begin{array}{l}\text { Forest cover } \\
\text { Position }\end{array}$ & $\begin{array}{l}0.06 \\
0.007\end{array}$ & $\begin{array}{l}0.77 \pm 0.42 \text { (slope) } \\
2.52 \pm 0.37 \text { (edge) } \\
2.04 \pm 0.18 \text { (interior) }\end{array}$ \\
\hline Simpson's diversity index (n) & $\begin{array}{l}\text { Forest cover } \\
\text { Position }\end{array}$ & $\begin{array}{l}0.03 \\
0.09\end{array}$ & $\begin{aligned}-1.64 & \pm 0.73 \text { (slope) } \\
3.68 & \pm 0.34 \text { (edge) } \\
3.32 & \pm 0.21 \text { (interior) }\end{aligned}$ \\
\hline Pielou's evenness index (n) & Forest cover & 0.01 & $\begin{aligned} 0.84 & \pm 0.05 \text { (intercept) } \\
-0.23 & \pm 0.09 \text { (slope) }\end{aligned}$ \\
\hline Phylogenetic richness (n) & Position & 0.03 & $\begin{array}{l}572.14 \pm 64.09 \text { (edge) } \\
462.23 \pm 49.16 \text { (interior) }\end{array}$ \\
\hline Phylogenetic diversity (n) & $\begin{array}{l}\text { Forest cover } \\
\text { Position } \\
\text { Interaction }\end{array}$ & $\begin{array}{l}0.12 \\
0.14 \\
0.02\end{array}$ & $\begin{array}{c}-17.67 \pm 10.84 \text { (slope: edge) } \\
-30.37 \pm 12.85 \text { (slope: interior) } \\
55.85 \pm 4.99 \text { (edge) } \\
64.54 \pm 5.71 \text { (interior) }\end{array}$ \\
\hline Phylogenetic evenness (n) & - & - & $367.41 \pm 19.48$ (intercept) \\
\hline Functional diversity (n) & Position & 0.02 & $\begin{array}{l}0.57 \pm 0.03 \text { (edge) } \\
0.48 \pm 0.04 \text { (interior) }\end{array}$ \\
\hline Functional evenness (n) & Forest cover & 0.07 & $\begin{aligned}-0.17 & \pm 0.09 \text { (slope) } \\
0.74 & \pm 0.04 \text { (intercept) }\end{aligned}$ \\
\hline
\end{tabular}

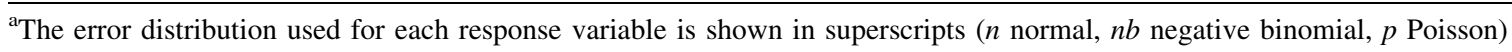

${ }^{\mathrm{b}}$ Dashes are used for cases where no independent variable showed a significant relationship

(50\% of total abundance), followed by generalized Myrmicinae (32\%). Simpson diversity index for functional groups was higher at the edge than at forest interior (Fig. 2c; Table 1), whereas functional evenness showed a marginal negative relationship with forest cover (Fig. 2d; Table 1). Edges contained more species and individuals of dominant Dolichoderinae and generalized Myrmicinae, and a tendency for more individuals of cryptic species in comparison with the forest interior, whereas the other groups did not show significant differences between positions (Fig. 3; Table 2). The effects of habitat loss varied among groups, with negative, neutral and positive responses being detected. Abundance of fungus-growing ants increased with forest cover, and richness of this group and cryptic species increased with fragment area (Fig. A1a-c; Table 2), although the latter case was only a weak tendency. Conversely, abundance and richness of opportunist and predator species decreased as forest cover in the landscape increased (Fig. A1d-g;
Table 2), although the relationships with predators were marginal.

Effects on community composition and mechanisms involved

Global community dissimilarity, measured with the Bray-Curtis index, was high $\left(\beta_{\text {bra }}=0.969\right)$ and most of the variation was due to species replacement $\left(\beta_{\text {bal }}=0.947\right)$, while species loss only explained a small fraction of community dissimilarity ( $\beta_{\text {gra- }}$ $=0.022$ ). Distance-based RDAs revealed that both $\beta_{\text {bra }}$ and $\beta_{\text {bal }}$ were influenced by fragment area (Fig. A2a, b; Table 3), although the proportion of explained inertia by fragment area was low (0.034 and 0.039 , respectively), with a higher influence of year, as the conditioning factor, in community composition (0.189 and 0.229). Changes in composition due to a gradient in species abundance, i.e. species loss $\left(\beta_{\text {gra }}\right)$, were explained by an interaction between position and 

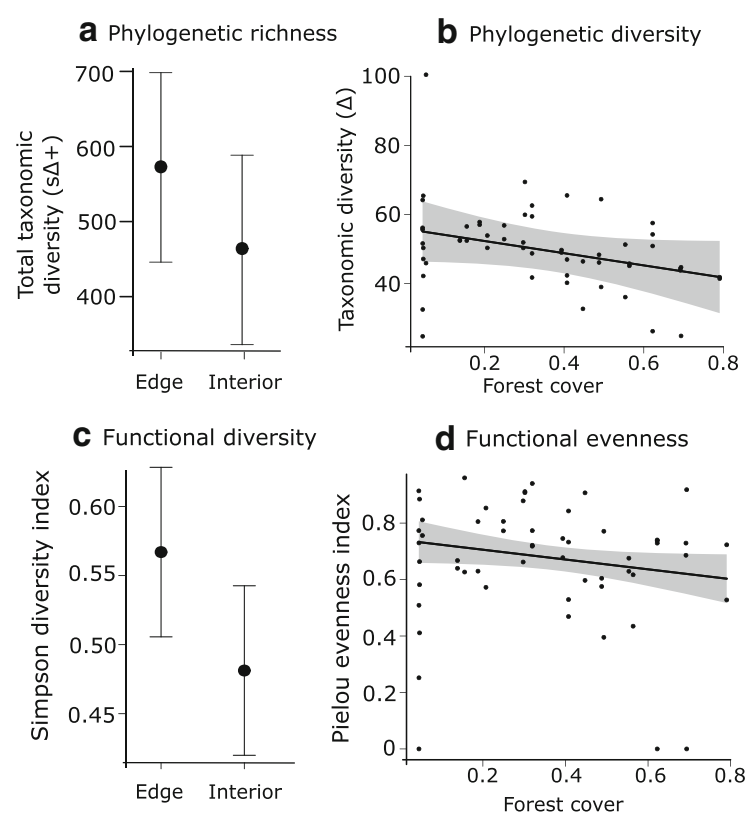

Fig. 2 Phylogenetic richness (a), phylogenetic diversity (b), functional diveristy (Simpson's index; c), and functional evenness (Pielou's index; d) of ant communities in fragmented Chaco Serrano forest (mean per trap $\pm 95 \%$ confidence intervals). Habitat loss (slopes $\pm 95 \% \mathrm{CI}$ and partial residuals) and edge effects (mean $\pm 95 \% \mathrm{CI}$ ) are shown. In (b) only the significant relationship with funcitonal diversity at the interior (regression line and CI) is shown

forest cover (Fig. A2c; Table 3), with a clearer difference between edge and interior in sites with high forest cover.

Changes in functional composition of ant communities were also mainly explained by a balanced replacement of functional groups and individuals, although the relative importance of the loss component was higher for functional than for taxonomic assemblages $\left(\beta_{\text {bra }}=0.959 ; \beta_{\text {bal }}=0.83 ; \beta_{\text {gra }}=0.129\right)$. Total beta diversity was related to forest cover, although $\beta_{\text {bal }}$ was not significantly related to any of the independent factors (Fig. A3a, b; Table 3). Changes in functional composition due to species loss were explained by an interaction between position and forest cover (Fig. A3c; Table 3).

\section{Discussion}

Natural ecosystems immersed in managed landscapes are influenced by the surrounding environment at multiple scales, from local edge effects at the boundaries between habitats to landscape-scale processes such as habitat loss. In turn, insect communities are affected in different ways, although their functional responses have only recently been addressed (Gagic et al. 2015; Gámez-Virués et al. 2015) and evidence from Neotropical dry forests is still scarce (Leal et al. 2012). Here, we studied the effects of forest loss and edge habitats on ants, a diverse, dominant and functionally relevant insect group, in the highly endangered Chaco Serrano forests from central Argentina. As expected, edge effects were mostly positive, with edges harboring higher ant abundance and diversity than the forest interior. Responses to habitat loss were more varied, particularly within functional groups, suggesting that changes in ecosystem functioning might be observed in crop-dominated landscapes. Finally, ant community changes linked to forest fragmentation involved replacement as well as loss/gain of species and functional groups.

\section{Taxonomic diversity}

Although agricultural fields suffer periodic disturbances associated with management practices (Nanni and Grau 2014) which might negatively affect neighboring land, edges of natural habitats adjacent to such fields are usually more diverse than interiors as showed for several groups of herbivores (Wirth et al. 2008) and insect communities (González et al. 2017b). This pattern has also been frequently shown for ants (Dejean and Gibernau 2000; Vasconcelos et al. 2001; Barrera et al. 2015), and the communities of Chaco Serrano fragments studied here responded in the same way. A possible explanation is that edges facilitate access to resources from adjacent habitats (Ries et al. 2004), although edge specialists, (i.e., species displaying a high fidelity to edge habitats), could also have contributed to the observed results (Duelli et al. 1990; Ries and Sisk 2010). In fact, our analyses showed that four ant species (Pheidole rosae, Apterostigma sp1, Brachymyrmex $\mathrm{sp} 1$ and Dorymyrmex $\mathrm{sp} 1$ ) may be considered indicators of edge conditions. Taken together these explanations suggest that multiple mechanisms could be leading to higher edge diversity. Similar mechanisms drove carabids communities in forest patches (Magura, 2002) and are consistent with larger edge than area effects for ground-dwelling arthropods in general (Golden and Crist 2000). 

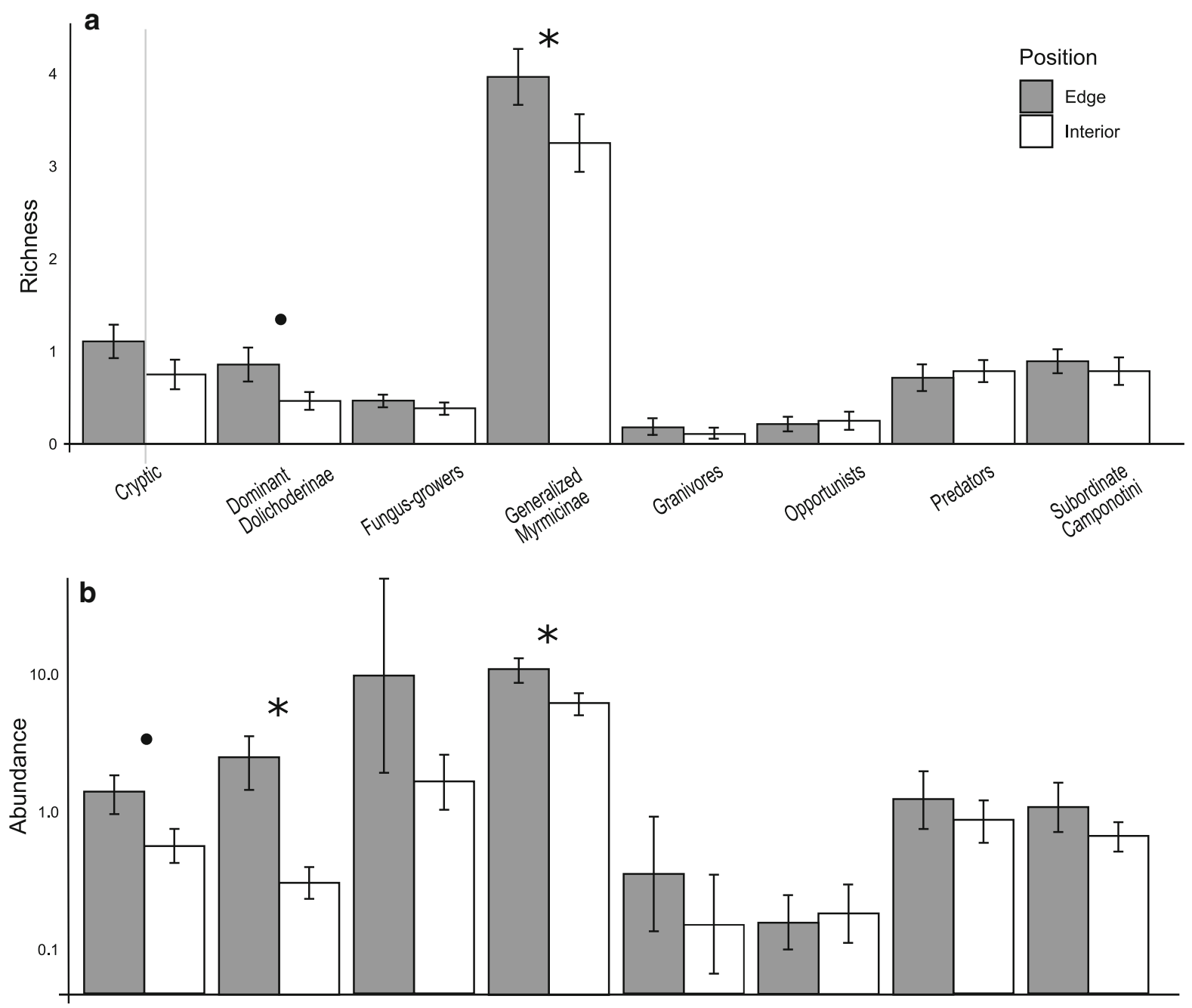

Fig. 3 Species richness (a) and abundance (b) of ant functional groups in fragmented Chaco Serrano forest. Means per trap \pm standard error are shown. Stars and dots represent significant and marginal differences, respectively

Conversely, ant responses to habitat loss were highly variable: although species richness was not affected, the amount of forest cover in the landscape was negatively related to evenness and diversity of ant communities but positively related to their total abundance. Thus, only abundance followed our predictions of negative effects of habitat loss and this relation was only marginal. The inverse pattern might arise from habitat configuration and availability. As fragmentation increases, patches are smaller, with a higher proportion of edges (Bogaert et al. 1999), which facilitates access to resources from both forest and crop matrix, benefitting edge and generalist species (Bestelmeyer and Wiens 2001; Neves et al. 2013).

Phylogenetic diversity

When we looked for edge and habitat loss effects by incorporating the phylogenetic relationships among ant species (Moreno et al. 2009), we obtained similar patterns to those from standard taxonomic measures. Thus, our results revealed that edges do not only support more species, but appear to be also richer from an evolutionary viewpoint by hosting a higher number of clades. 
Table 2 Effects of habitat loss and edge/interior position on functional groups of ants in fragmented Chaco Serrano forest

\begin{tabular}{|c|c|c|c|c|}
\hline Functional group & Response variable ${ }^{\mathrm{a}}$ & Independent variables ${ }^{\mathrm{b}}$ & P-value & Estimates ( \pm S.E.) \\
\hline \multirow[t]{2}{*}{ Cryptic species } & Richness (p) & Fragment area & 0.07 & $\begin{aligned} 0.27 & \pm 0.15 \text { (slope) } \\
-0.39 & \pm 0.31 \text { (intercept) }\end{aligned}$ \\
\hline & Abundance (n) & Position & 0.08 & $\begin{array}{l}1.46 \pm 0.40 \text { (edge) } \\
0.64 \pm 0.45 \text { (interior) }\end{array}$ \\
\hline \multirow[t]{2}{*}{ Dominant Dolichoderinae } & Richness (p) & Position & 0.07 & $\begin{array}{l}-0.17 \pm 0.24 \text { (edge) } \\
-0.78 \pm 0.34 \text { (interior) }\end{array}$ \\
\hline & Abundance (n) & Position & 0.03 & $\begin{array}{l}2.54 \pm 0.99 \text { (edge) } \\
0.36 \pm 1.00 \text { (interior) }\end{array}$ \\
\hline \multirow[t]{2}{*}{ Fungus-growers } & Richness (p) & Fragment area & 0.02 & $\begin{aligned} 0.30 & \pm 0.13 \text { (slope) } \\
-1.17 & \pm 0.21 \text { (intercept) }\end{aligned}$ \\
\hline & Abundance (nb) & Forest cover & 0.0001 & $\begin{array}{c}2.60 \pm 0.62 \text { (slope) } \\
-1.06 \pm 0.001 \text { (intercept) }\end{array}$ \\
\hline \multirow[t]{2}{*}{ Generalized Myrmicinae } & Richness (p) & Position & 0.03 & $\begin{array}{l}0.80 \pm 0.13 \text { (edge) } \\
0.55 \pm 0.11 \text { (interior) }\end{array}$ \\
\hline & Abundance (nb) & Position & 0.008 & $\begin{array}{l}2.02 \pm 0.32 \text { (edge) } \\
1.54 \pm 0.18 \text { (interior) }\end{array}$ \\
\hline \multirow[t]{2}{*}{ Granivores } & Richness (p) & - & - & $-2.34 \pm 0.77$ (intercept) \\
\hline & Abundance (p) & - & - & $0.04 \pm 0.03$ (intercept) \\
\hline \multirow[t]{2}{*}{ Opportunists } & Richness (p) & Forest cover & 0.01 & $\begin{array}{l}-3.61 \pm 1.52 \text { (slope) } \\
-0.63 \pm 0.60 \text { (intercept) }\end{array}$ \\
\hline & Abundance (n) & Forest cover & 0.01 & $\begin{aligned}-0.63 & \pm 0.24 \text { (slope) } \\
0.43 & \pm 0.14 \text { (intercept) }\end{aligned}$ \\
\hline \multirow[t]{2}{*}{ Predators } & Richness (p) & Forest cover & 0.1 & $\begin{aligned}-1.15 & \pm 0.72 \text { (slope) } \\
0.07 & \pm 0.26 \text { (intercept) }\end{aligned}$ \\
\hline & Abundance (n) & Forest cover & 0.08 & $\begin{aligned}-2.67 & \pm 1.48 \text { (slope) } \\
2.08 & \pm 0.63 \text { (intercept) }\end{aligned}$ \\
\hline \multirow[t]{2}{*}{ Subordinate Camponotini } & Richness (p) & - & - & $-0.10 \pm 0.24$ (intercept) \\
\hline & Abundance (n) & - & - & $0.73 \pm 0.26$ (intercept) \\
\hline
\end{tabular}

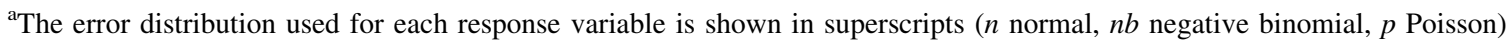

${ }^{\mathrm{b}}$ Dashes are used for cases where no independent variable showed a significant relationship

Moreover, phylogenetic diversity was, like Simpson's diversity, negatively related to forest cover, albeit this decrease was only relevant at the forest interior. This suggests that the impoverishment of ant communities in forest-dominated landscapes might reflect a decreased influx of species from the agricultural matrix (Kupfer et al. 2006). Since responses to edge and matrix habitats are species-specific (Kupfer et al. 2006), it seems likely that less-related species would tend to show more dissimilar responses, which might underlie an increase in phylogenetic diversity in crop-dominated landscapes, where small forest remnants offer a proportionally larger exchange area with the matrix.

\section{Functional diversity}

The analyses of functional groups revealed general patterns as well as different responses from particular groups. Overall functional diversity was higher at the edge, suggesting that the higher taxonomic diversity observed in these habitats has consequences for the ecosystem processes in which ants are involved, especially those related to soil dynamics and nutrient cycling (Jones et al. 1994; Folgarait 1998). In particular, positive edge effects were detected for generalized Myrmicinae, dominant Dolichoderinae and cryptic species, each of them including an edge specialist species (according to the indicator species 
Table 3 Results from distance-based redundancy analyses performed with dissimilarity matrices of beta diversity components (taxonomic and functional) of ant communities in Chaco Serrano fragmented forest

\begin{tabular}{|c|c|c|c|c|}
\hline \multirow[t]{2}{*}{ Beta diversity component ${ }^{\mathrm{a}}$} & \multicolumn{2}{|l|}{ Constrained $^{\mathrm{b}}$} & \multirow[t]{2}{*}{ Conditional } & \multirow[t]{2}{*}{ Unconstrained } \\
\hline & Variance explained & Independent variables $^{c}$ & & \\
\hline Taxonomic composition & 0.03 & Fragment area** & 0.19 & 0.78 \\
\hline Species replacement & 0.04 & Fragment area* & 0.23 & 0.73 \\
\hline Species loss/gain & 0.17 & Forest cover $\times$ position $*$ & -0.11 & 0.95 \\
\hline Functional composition & 0.04 & Forest cover* & 0.14 & 0.82 \\
\hline Functional group replacement & - & - & -0.1 & 1.1 \\
\hline Functional group loss/gain & 0.10 & Forest cover $\times$ position* & 0.38 & 0.52 \\
\hline
\end{tabular}

${ }^{a}$ Species and functional group replacement refers to balanced changes in abundances, while species/functional group loss/gain refers to gradients in abundance

${ }^{b}$ For each matrix, the proportion of inertia explained by constrained, conditional (year) and unconstrained components is showed

${ }^{\mathrm{c}}$ Independent variables included in the formula of the best models are shown, with their P-value indicated in superscripts $(* \mathrm{p}<0.05$; $* * \mathrm{p}<0.01)$

analyses), which may have contributed to the group tendency. Interestingly, no functional group seemed to benefit from conditions at the forest interior. Previous studies of edge effects have also found a majority of positive responses for different trophic guilds (Wirth et al. 2008; González et al. 2015a).

Although more nests of leaf-cutting ants had been recorded on the edges than at the interior of the same forests here studied (Barrera et al. 2015), we found similar activity of these ants in both habitats. Our results, together with the detection of Acromyrmex workers on soybean plants (González et al. 2017a), indicate that at least some leaf-cutting species use resources from both forest and matrix habitats, and access to the latter might explain the choice of edge habitats for nesting. Of course, not all species within a functional group will necessarily show identical responses; thus, predators as a group did not show particular preference for either position in our study and yet, within the same region, predation rates by ants on artificial caterpillars were higher at the forest interior than at the edge (Ferrante et al. 2017), which might reflect species-specific preferences.

Forest cover did not affect ant functional diversity but was negatively related to abundance and richness of opportunists, as well as (marginally) predators and functional evenness. The greater proportion of edge habitats in landscapes with reduced forest cover might explain these trends by supporting more functional groups, particularly generalist ants such as opportunists and predators, in exploiting different resources from forest and matrix (Brandão et al. 2012). Conversely, fungus-growing ants and cryptic species increased with forest area. For the first group, this increase confirms the sensitivity to forest area shown by leaf-cutter ants (Barrera et al. 2015), which were a dominant component within fungus-growers. Cryptic species are considered a specialized group, and they were also shown to be sensitive to forest fragmentation in Brazil (Leal et al. 2012); specialization is considered a trait conferring high vulnerability to habitat loss (Cagnolo et al. 2009). Changes in functional groups could alter ecosystem processes and services, e.g. fewer species and individuals of dung beetles resulted in lower rates of dung decomposition in small forest fragments (Klein 1989).

Effects on community composition and mechanisms involved

Partition of taxonomic beta diversity revealed that most of the variation in ant community composition was due to species replacement, as balanced changes in species abundance meant a relatively stable regional pool of species with varying number of individuals at each site, leading to species turnover between fragments. Other studies have also found larger contributions of species replacement in comparison with species loss at local and landscape scales (Schmidt et al. 2017), while the species loss/gain component seems to be more important at regional or even larger scales (Schmidt et al. 2017) or in regions where strong 
environmental or historic gradients occur (Baselga 2010). In our Chaco Serrano forest, taxonomic and functional composition were poorly affected by edge/ interior position, indicating that the higher diversity consistently found at the edges was not strongly linked to a compositional pattern. Moreover, although we included sampling year as a conditional factor in the analyses, its influence suggests large temporal changes in ant community composition, including both replacement and loss/gain of species.

Both total taxonomic composition and the turnover component were affected by fragment area, indicating that fragments of similar size are inhabited by similar sets of species. Thus, despite habitat loss not leading to a decrease in ant species number, replacement of species in small fragments occurred, which may be linked to an increase in edge-specialist and matrix species and a decrease of species susceptible to habitat loss, such as rare or specialist species (Cagnolo et al. 2009). Both mechanisms were previously observed in ant comunnities of Brazil by Sobrinho et al. (2003), who found that small forest fragments had fewer forest species and a higher proportion of generalist species shared with the matrix. Also, the identity of species gained or lost at the forest edge or at the interior seems to depend on the size of the fragment, according to the interaction observed. These findings could be related to those of Sobrinho and Schoereder (2007), who observed that edge/interior similarity decreased as fragment area increased, which in our case was reflected differentially for replacement and species loss/gain.

Differences in functional composition of ant communities were also driven mainly by replacement of functional groups, but here the relative importance of the loss/gain component was almost six times higher than in the taxonomic analysis. Thus, loss/gain of functional groups was more pronounced than the loss of ant species in this fragmented forest. Functional diversity may be a better predictor of ecosystem services than species diversity (Gagic et al. 2015) therefore, ecosystem functions in which ants are involved could suffer stronger alterations than what changes in taxonomic diversity and composition might lead us to expect. Changes in total functional composition were influenced by forest cover, reinforcing the relevance of habitat loss for particular functional groups (Leal et al. 2012), which may in turn affect ecosystem processes such as herbivory (Blanton and Ewel 1985). Given the impact of the interaction between forest cover and position for the functional composition of the studied assemblages, both factors need to be considered when addressing changes in ecosystem functions performed by ant communities.

\section{Conclusions}

Fragmented natural habitats are becoming increasingly common, but although many studies have addressed the effects of habitat fragmentation on insect communities, we know of no previous study simultaneously considering habitat loss and edge effects on taxonomic and functional community structure and at the same time exploring possible mechanisms underlying biodiversity changes. Our results showed ant communities in Chaco Serrano forests responding to habitat loss and edge effects in a variety of ways. While edges presented higher diversity of species and abundance of total ants and particular functional groups, habitat loss affected community structure, functional groups and taxonomic and functional composition, with species replacement as the most influential mechanism.

The implications of these results are relevant for biodiversity conservation and ecosystem functioning of this endangered ecosystem. Small forest patches located in predominantly agricultural landscapes sustained more diverse communities, taxonomically as well as functionally, suggesting that maintaining small remnants of native vegetation can contribute to sustaining biodiversity and ecosystem services in cultivated landscapes, as proposed in the framework of land sharing (Fischer et al. 2014). However, some groups were enhanced in forest-dominated landscapes, supporting conservation of the few large forest patches that are still present in central Argentina. The strong positive edge effects here observed highlight the need for further studies addressing ant communities within the matrix and the possible spillover between crop and forest in order to understand their mutual influence. Furthermore, the observed changes in functional community structure demand additional research focusing on the ecosystem services and disservices provided by ants in such fragmented landscapes. 
Acknowledgements We are thankful to the field owners that allowed us to work in their lands, to field assistants for their valuable help and to two anonymous reviewers for their helpful suggestions.

Funding This work was performed with grants from the National Scientific and Technical Research Council or Argentina (CONICET; PIP 112201201 00662), the Secretariat of Science and Technology of Córdoba (SECyT) and with an Internal Grant Agency of the Faculty of Environmental Sciences at the Czech University of Life Sciences Prague (Grants No. 42900/1312/3166).

Data availability The datasets analyzed during the current study are available online at http://dx.doi.org/10.17632/ cwrkdvevxn.1

\section{Compliance with ethical standards}

Conflicts of interest The authors declare that there are no financial or other types of conflicts of interest that bias this work.

\section{References}

Andersen AN (1995) A classification of Australian ant communities, based on functional groups which parallel plant life-forms in relation to stress and disturbance. J Biogeogr 22:15-29

Barrera CA, Buffa LM, Valladares G (2015) Do leaf-cutting ants benefit from forest fragmentation? Insights from community and species-specific responses in a fragmented dry forest. Insect Conserv Divers 8:456-463

Bartoń K (2009) MuMIn: multi-model inference. R package, version 0.12. 2. http://CRAN.R-project.org/. Accessed 20 June 2018

Baselga A (2010) Partitioning the turnover and nestedness components of beta diversity. Glob Ecol Biogeogr 19:134-143

Baselga A (2013) Separating the two components of abundancebased dissimilarity: balanced changes in abundance vs. abundance gradients. Methods Ecol Evol 4:552-557

Baselga A (2017) Partitioning abundance-based multiple-site dissimilarity into components: balanced variation in abundance and abundance gradients. Methods Ecol Evol 8:799-808

Baselga A, Orme CDL (2012) betapart: an R package for the study of beta diversity. Methods Ecol Evol 3:808-812

Bates D, Sarkar D (2007) lme4: Linear mixed-effects models using S4 classes. R package version 0.9975-12. http:// CRAN.R-project.org/. Accessed 20 June 2018

Bestelmeyer BT, Wiens JA (2001) Ant biodiversity in semiarid landscape mosaics: the consequences of grazing vs. natural heterogeneity. Ecol Appl 11:1123-1140

Bishop TR, Robertson MP, van Rensburg BJ, Parr CL (2015) Contrasting species and functional beta diversity in montane ant assemblages. J Biogeogr 42:1776-1786

Blanton CM, Ewel JJ (1985) Leaf-cutting ant herbivory in successional and agricultural tropical ecosystems. Ecology $66: 861-869$
Blitzer EJ, Dormann CF, Holzschuh A, Klein AM, Rand TA, Tscharntke T (2012) Spillover of functionally important organisms between managed and natural habitats. Agric Ecosyst Environ 146:34-43

Bogaert J, Van Hecke P, Impens I (1999) A reference value for the interior-to-edge ratio of isolated habitats. Acta Biotheor 47:67-77

Brandão CR, Silva RR, Delabie JH (2012) Neotropical ants (Hymenoptera) functional groups: nutritional and applied implications. In: Panizzi AR, Parra JRP (eds) Insect bioecology and nutrition for integrated pest management. CRC Press, Boca Raton, pp 213-236

Breheny P, Burchett W (2016) visreg: visualization of regression models. $\mathrm{R}$ package version 2.5-0. http://CRAN.Rproject.org/. Accessed 23 September 2018

Cabido M, Carranza ML, Acosta A, Páez S (1991) Contribución al conocimiento fitosociológico del Bosque Chaqueño Serrano en la provincia de Córdoba, Argentina. Phytocoenología 19:547-566

Cagnolo L, Valladares G, Salvo A, Cabido M, Zak M (2009) Habitat fragmentation and species loss across three interacting trophic levels: effects of life-history and food-web traits. Conserv Biol 23:1167-1175

Carvalho KS, Vasconcelos HL (1999) Forest fragmentation in central Amazonia and its effects on litter-dwelling ants. Biol Conserv 91:151-157

Claver S, Silnik SL, Campón FF (2014) Response of ants to grazing disturbance at the central Monte Desert of Argentina: community descriptors and functional group scheme. J Arid Land 6:117-127

De Cáceres M, Jansen F, De Caceres MM (2016) Package 'indicspecies'. R package version 1. 7.6. http://CRAN.Rproject.org/. Accessed 20 June 2018

Debuse VJ, King J, House AP (2007) Effect of fragmentation, habitat loss and within-patch habitat characteristics on ant assemblages in semi-arid woodlands of eastern Australia. Landscape Ecol 22:731-745

Dejean A, Gibernau M (2000) A rainforest ant mosaic: the edge effect (Hymenoptera: Formicidae). Sociobiology 35:385-402

Duelli P, Obrist MK (2003) Regional biodiversity in an agricultural landscape: the contribution of seminatural habitat islands. Basic Appl Ecol 4:129-138

Duelli P, Studer M, Marchand I, Jakob S (1990) Population movements of arthropods between natural and cultivated areas. Biol Conserv 54:193-207

Dunn RR (2004) Managing the tropical landscape: a comparison of the effects of logging and forest conversion to agriculture on ants, birds, and Lepidoptera. For Ecol Manag 191:215-224

Fahrig L (2003) Effects of habitat fragmentation on biodiversity. Annu Rev Ecol Evol Syst 34:487-515

Fernández F (2003) Introducción a las hormigas de la región Neotropical. Instituto de Investigación de Recursos Biológicos Alexander von Humboldt, Bogotá

Ferrante M, González E, Lövei GL (2017) Predators do not spill over from forest fragments to maize fields in a landscape mosaic in central Argentina. Ecol Evol 7:7699-7707

Fischer J, Abson DJ, Butsic V, Chappell MJ, Ekroos J, Hanspach J, Kuemmerle T, Smith HG, Wehrden H (2014) Land 
sparing versus land sharing: moving forward. Conserv Lett 7:149-157

Folgarait PJ (1998) Ant biodiversity and its relationship to ecosystem functioning: a review. Biodivers Conserv $7: 1221-1244$

Fox J (2003) Effect displays in R for generalized linear models. J Stat Softw 8:1-27

Gagic V, Bartomeus I, Jonsson T, Taylor A, Winqvist C, Fischer C, Slade EM, Steffan-Dewenter I, Emmerson M, Potts SG, Tscharntke T, Weisser W, Bommarco R (2015) Functional identity and diversity of animals predict ecosystem functioning better than species-based indices. Proc R Soc Lond B 282:20142620

Gámez-Virués S, Perović DJ, Gossner MM, Börschig C, Blüthgen N, De Jong H, Simons NK, Klein AM, Krauss J, Maier G, Scherber C, Steckel J, Rothenwöhrer C, SteffanDewenter I, Weiner CN, Weisser W, Werner M, Tscharntke T, Westphal C (2015) Landscape simplification filters species traits and drives biotic homogenization. Nat Commun 6:8568

Gaston KJ, Blackburn TM (2000) Pattern and process in macroecology. Blackwell Science, Oxford

Golden DM, Crist TO (2000) Experimental effects of habitat fragmentation on rove beetles and ants: patch area or edge? Oikos 90:525-538

González E, Salvo A, Valladares G (2015a) Arthropods on plants in a fragmented Neotropical dry forest: a functional analysis of area loss and edge effects. Insect Sci 22:129-138

González E, Salvo A, Valladares G (2015b) Sharing enemies: evidence of forest contribution to natural enemy communities in crops, at different spatial scales. Insect Consev Divers 8:359-366

González E, Salvo A, Defagó MT, Valladares G (2016) A moveable feast: insects moving at the forest-crop interface are affected by crop phenology and the amount of forest in the landscape. PLoS ONE 11:e0158836

González E, Salvo A, Valladares G (2017a) Arthropod communities and biological control in soybean fields: forest cover at landscape scale is more influential than forest proximity. Agric Ecosyst Environ 239:359-367

González E, Salvo A, Valladares G (2017b) Natural vegetation cover in the landscape and edge effects: differential responses of insect orders in a fragmented forest. Insect Sci 24:891-901

Grau RH, Gasparri NI, Aide M (2008) Balancing food production and nature conservation in the Neotropical dry forests of northern Argentina. Glob Change Biol 14:985-997

Haddad NM, Brudvig LA, Clobert J, Davies KF, Gonzalez A, Holt RD, Lovejoy TE, Sexton JO, Austin MP, Collins CD, Cook WM, Damschen EI, Ewers RM, Foster BL, Jenkins $\mathrm{CN}$, King AJ, Laurance WF, Levey DJ, Margules CR, Melbourne BA, Nicholls AO, Orrock JL, Song D, Townshend JR (2015) Habitat fragmentation and its lasting impact on Earth's ecosystems. Sci Adv 1:e1500052

Hölldobler B, Wilson EO (1990) The ants. Harvard University Press, Cambridge

Hurvich CM, Tsai CL (1989) Regression and time series model selection in small samples. Biometrika 76:297-307

Jones CG, Lawton JH, Shachak M (1994) Organisms as ecosystem engineers. Oikos 69:373-386
Klein BC (1989) Effects of forest fragmentation on dung and carrion beetle communities in central Amazonia. Ecology 70:1715-1725

Kupfer JA, Malanson GP, Franklin SB (2006) Not seeing the ocean for the islands: the mediating influence of matrixbased processes on forest fragmentation effects. Glob Ecol Biogeogr 15:8-20

Leal IR, Filgueiras BK, Gomes JP, Iannuzzi L, Andersen AN (2012) Effects of habitat fragmentation on ant richness and functional composition in Brazilian Atlantic forest. Biodivers Conserv 21:1687-1701

Legendre P, Anderson MJ (1999) Distance-based redundancy analysis: testing multispecies responses in multifactorial ecological experiments. Ecol Monogr 69:1-24

Magura T (2002) Carabids and forest edge: spatial pattern and edge effect. For Ecol Manag 157:23-37

Magurran AE (2004) Measuring biological diversity. Blackwell, Oxford

Majer JD, Delabie JHC, McKenzie NL (1997) Ant litter fauna of forest, forest edges and adjacent grassland in the Atlantic rain forest region of Bahia, Brazil. Insect Soc 44:255-266

McGarigal K, Cushman SA (2002) Comparative evaluation of experimental approaches to the study of habitat fragmentation effects. Ecol Appl 12:335-345

Moreno CE, Castillo-Campos G, Verdú JR (2009) Taxonomic diversity as complementary information to assess plant species diversity in secondary vegetation and primary tropical deciduous forest. J Veg Sci 20:935-943

Nanni AS, Grau HR (2014) Agricultural adjustment, population dynamics and forests redistribution in a subtropical watershed of NW Argentina. Reg Environ Change 14:1641-1649

Neves FS, Queiroz-Dantas KS, Da Rocha WD, Delabie JHC (2013) Ants of three adjacent habitats of a transition region between the Cerrado and Caatinga biomes: the effects of heterogeneity and variation in canopy cover. Neotrop Entomol 42:258-268

Oksanen J, Blanchet FG, Kindt R, Legendre P, Minchin PR, O'hara RB, Simpson GL, Solymos P, Henry M, Stevens H, Szoecs E, Wagner H (2013) Package 'vegan'. Community ecology package version 2(9). http://CRAN.R-project.org/. Accessed 20 June 2018

Perfecto I, Armbrecht I, Philpott SM, Soto-Pinto L, Dietsch TV (2007) Shaded coffee and the stability of rainforest margins in Latin America. In: Tscharntke T, Leuschner C, Zelle M, Guhadja E, Bidin A (eds) The stability of tropical rainforest margins: linking ecological, economic and social constraints of land use and conservation. Springer Verlag, Berlin, pp 227-263

Philpott SM, Perfecto I, Armbrecht I, Parr CL (2010) Ant diversity and function in disturbed and changing habitats. In: Lach L, Parr C, Abbott K (eds) Ant ecology. Oxford University Press, Oxford, pp 137-156

Pimm SL, Raven P (2000) Biodiversity: extinction by numbers. Nature 403:843-845

Pinheiro J, Bates D, DebRoy S, Sarkar D, the R Development Core Team (2013) nlme: linear and nonlinear mixed effects models. R package version 3.1-109. http://CRAN.Rproject.org/. Accessed 20 June 2018

R Development Core Team (2008) R: A language and environment for statistical computing. $\mathrm{R}$ Foundation for 
Statistical Computing, Vienna, Austria. http://www.Rproject.org. Accessed 20 May 2018

Rand TA, Tylianakis JM, Tscharntke T (2006) Spillover edge effects: the dispersal of agriculturally subsidized insect natural enemies into adjacent natural habitats. Ecol Lett 9:603-614

Ries L, Sisk TD (2010) What is an edge species? The implications of sensitivity to habitat edges. Oikos 119:1636-1642

Ries L, Fletcher RJ Jr, Battin J, Sisk TD (2004) Ecological responses to habitat edges: mechanisms, models, and variability explained. Annu Rev Ecol Evol Syst 35:491-522

Schmidt FA, Ribas CR, Sobrinho TG, Ubaidillah R, Schoereder JH, Clough Y, Tscharntke T (2017) Similar alpha and beta diversity changes in tropical ant communities, comparing savannas and rainforests in Brazil and Indonesia. Oecologia 185:487-498

Sobrinho TG, Schoereder JH (2007) Edge and shape effects on ant (Hymenoptera: Formicidae) species richness and composition in forest fragments. Biodivers Conserv 16:1459-1470

Sobrinho TG, Schoereder JH, Sperber CF, Madureira MS (2003) Does fragmentation alter species composition in ant communities (Hymenoptera: Formicidae)? Sociobiology 42:329-342

Soininen J, Heino J, Wang J (2018) A meta-analysis of nestedness and turnover components of beta diversity across organisms and ecosystems. Glob Ecol Biogeogr 27:96-109

Southwood TRE, Henderson PA (2000) Ecological methods. Blackwell Science, London
Suarez AV, Bolger DT, Case TJ (1998) Effect of fragmentation and invasion on native ant communities in coastal Southern California. Ecology 79:2041-2056

Tilman D, Fargione J, Wolff B, D'Antonio C, Dobson A, Howarth R, Schindler D, Schlesinger WH, Simberloff D, Swackhamer D (2001) Forecasting agriculturally driven global environmental change. Science 292:281-284

Vasconcelos HL, Carvalho KS, Delabie JH (2001) Landscape modifications and ant communities. In: Bierregaard RO Jr, Gascon C, Lovejoy TE, Mesquita R (eds) Lessons from Amazonia: the ecology and conservation of a fragmented forest. Yale University Press, New Haven, pp 199-207

Warwick RM, Clarke KR (1995) New ‘biodiversity' measures reveal a decrease in taxonomic distinctness with increasing stress. Mar Ecol Prog Ser 129:301-305

Wirth R, Meyer ST, Leal IR, Tabarelli M (2008) Plant herbivore interactions at the forest edge. In: Lüttge U, Beyschlag W, Murata J (eds) Progress in botany. Springer, Berlin, Heidelberg, pp 423-448

Zak MR, Cabido M, Hodgson JG (2004) Do subtropical seasonal forest in the Gran Chaco, Argentina, have a future? Biol Conserv 120:589-598

Zak MR, Cabido M, Cáceres D, Díaz S (2008) What drives accelerated land cover change in central Argentina? Synergistic consequences of climatic, socioeconomic, and technological factors. Environ Manage 42:181-189

Zuur AF, Ieno EN, Walker NJ, Saveliev AA, Smith GM (2009) Mixed effects models and extensions in ecology with R. Springer, New York 